\title{
Reconfigurable Fractional-Order Filter with Electronically Controllable Slope of Attenuation, Pole Frequency and Type of Approximation
}

JEŘÁBEK, J.; ŠOTNER, R.; DVOŘÁK, J.; POLÁK, J.; KUBÁNEK, D.; HERENCSÁR, N.; KOTON, J.

Journal of Circuits Systems and Computers

2017, vol. 26 , iss. 10 , pp. 1-21

ISSN (Print): 0218-1266

ISSN (Online): 1793-6454

DOl: http://dx.doi.org/10.1142/S0218126617501572

Accepted manuscript

Electronic version of an article published as Journal of Circuits Systems and Computers 2017, vol. 26, iss. 10, pp. 1-21, DOI 10.1142/S0218126617501572 @ 2017 World Scientific Publishing Company, http://www.worldscientific.com/worldscinet/jcsc 


\title{
Reconfigurable Fractional-Order Filter with Electronically Controllable Slope of Attenuation, Pole Frequency and Type of Approximation
}

Jan Jerabek*, Roman Sotner, Jan Dvorak, Josef Polak, David Kubanek, Norbert Herencsar and Jaroslav Koton

\author{
Department of Telecommunications, Brno University of Technology, Technicka 12, \\ Brno, 616 00, Czech Republic ${ }^{*}$ \\ jerabekj@feec.vutbr.cz. \\ sotner@feec.vutbr.cz \\ dvorakjan@phd.feec.vutbr.cz \\ xpolak24@phd.feec.vutbr.cz \\ kubanek@feec.vutbr.cz \\ herencsn@feec.vutbr.cz \\ koton@feec.vutbr.cz
}

Received (19 December 2016)

Revised (20 January 2017)

Accepted (2 February 2017)

\begin{abstract}
This paper presents design of electronically reconfigurable fractional-order filter that is able to be configured to operate as fractional-order low-pass filter (FLPF) or fractional-order high-pass filter (FHPF). Its slope of attenuation between pass band and stop band, i.e. order of the filter, is electronically adjustable in range between 1 and 2. Also pole frequency can be electronically controlled independently with respect to other tuned parameters. Moreover, particular type of approximation can be also controlled electronically. This feature set is available both for FLPF and FHPF type of response. Presented structure of the filter is based on well-known follow-the-leader feedback (FLF) topology adjusted in our case for utilization with just simple active elements operational transconductance amplifiers (OTAs) and adjustable current amplifiers (ACAs), both providing possibility to control its key parameter electronically. Paper explains how reconfigurable 3rd-order FLF topology is used in order to approximate both FLPF and FHPF in concerned frequency band of interest. Design is supported by PSpice simulations for three particular values of order of the filter $(1.25,1.5,1.75)$, for several values of pole frequency and for two particular types of approximation forming the shape of both the magnitude and phase response. Moreover, theoretical presumptions are successfully confirmed by laboratory measurements with prepared prototype based on behavioral modeling.
\end{abstract}

Keywords: adjustable current amplifier; approximation; ACA; fractional-order filter; fractional-order high-pass filter; fractional-order low-pass filter; FLF; follow-the-leader feedback; fractional order; operational transconductance amplifier; OTA; reconfigurable filter.

\section{Introduction}

Each analog circuit needs passive elements (resistors, capacitors, inductors in most cases). These passive elements are used for further synthesis together with active elements to create linear (integrators, amplifiers, ...) and nonlinear (comparators, shapers, switches, ...) functional blocks. Finally, these blocks create simple or complex applications (filters,

${ }^{*}$ Corresponding author. 
oscillators, generators, modulators, mixers, ...) that are implemented in complex mixed (analog and digital) systems (transceivers, systems for sensor processing, measuring devices, systems for communication, etc.). Common approaches in synthesis and design of linear circuits suppose integer order of the used passive reactive components and integer order of resulting functional block (and application). This fact results from character of commonly available (on the market) passive elements. Integer-order passive elements are currently easily producible because of technological aspects.

However, in some cases, also fractional-order systems ${ }^{1-3}$ are important due to their ability to describe real-world processes and phenomena. Many systems in nature have rather fractional character and nonlinear behavior that differs from their common linear and integer-order approximations used for better understanding and simpler modeling. Typical examples can be found in many analog systems for signal processing (filters, amplifiers, controllers, immittance circuits, etc.). For instance, we can mention modeling of impedance ${ }^{4}$ of biological tissue $e^{5}$ that is typical example of fractional-order behavior. The impedance characteristic of this biological matter can be modeled by fractional-order model where fractional-order passive elements are required.

There are two possibilities how to synthetize the fractional-order immittance elements. We can use standard synthesis when passive elements (capacitors in many cases) are directly replaced by elements with fractional character. There are several methods how to construct these elements ${ }^{6-8}$ (RC ladder structures and chains in the most cases). They are referred to as approximants because resulting two-terminal device provides only approximation of requested frequency characteristic (immittance) in limited frequency band and with certain phase ripple. These features depend on selected approximation, usually having polynomial character. There are even attempts to use only appropriate locations of zeros and poles of the immittance or transfer function (in case of two-port system) instead of any mathematical approximation (implemented in Mathcad ${ }^{9}$ ). These locations of poles and zeros frequencies can be also achieved quite simply by PSpice Optimizer tool for example $\mathrm{e}^{10-12}$.

The second method supposes synthesis of special replacement of fractional-order passive element (fractional-order capacitor in most cases) that is applied in original structure of the designed fractional-order systems. However, increased circuit complexity, power consumption, influences of real parasitic features of used active elements necessary for these solutions are substantial in many cases. Typical examples of this method are given $\mathrm{in}^{13,14}$. Note that fractional behavior of the two terminal system can be obtained as output response of the active filter of high-integer-order with appropriate setting of values of transfer coefficients (so-called continuous fraction expansion) supplemented with simple conversion of output signal into the input node ${ }^{14-16}$. Accuracy of the immittance is given by mathematical approximation used in such filter ${ }^{17,18}$ and by coefficients and order of the filter ${ }^{19,20}$. We can also use direct synthesis of the "active" immittance from required locations of zeros and poles ${ }^{21}$. This method is not using special polynomial mathematical approximations noted above. Required bandwidth of resulting approximant and corresponding phase ripple determines locations and number of these roots directly. This 
method leads to chains of many sub-block (so-called bilinear sections/immittances with independently adjustable poles and zeros ${ }^{21}$ ). Bilinear two-ports (building blocks, e.g. integrator) also exists ${ }^{11,22}$. The required phase ripple and bandwidth of validity of approximation determine the minimal number of necessary sections.

Note that real fractional-order devices (two-terminal systems) are developed and studied also as solid-state devices based on some chemical/technological mixtures, see for example to Ref. 23 - 25. There are also the very first attempts to prepare passive element having fractional-order features on $\mathrm{chip}^{26}$, however inventors are contending several issues and presented implementation has several drawbacks.

Usefulness of the fractional-order filters lays in possibility to set theoretically arbitrary slope of its magnitude response and also theoretically arbitrary maximal phase shift. Classic integer-order filters have steepness between pass and stop band given by $20 \cdot n$ $\mathrm{dB} / \mathrm{dec}$ where $n$ is nonzero integer value $\left(90^{\circ} \cdot n\right.$ for maximal phase shift in phase response) and depends significantly on number of independent accumulation elements (capacitor, inductors) present in the filtering structure. Fractional-order circuits (basic two-terminals and two ports, i.e. immittances, integrators, differentiators) generally have arbitrary slope of magnitude response $(20 \cdot a \mathrm{~dB} / \mathrm{dec})$ and maximal phase shift $\left(90^{\circ} \cdot a\right)^{11}$, where $a>0$ and $a$ is real number. However, this approach is not common because of its impracticality. General frequency response of the fractional-order filter is therefore frequently described by magnitude slope $20 \cdot(n+a) \mathrm{dB} / \mathrm{dec}$ and phase shift $90^{\circ} \cdot(n+a)$ as combination of integer and fractional part/contribution in filters with order higher than 1 ( $\mathrm{n} \geq 1$ and $0<a<1)$. Note that $a$ is also very often referred to as $\alpha$.

As already discussed, except investigation of solutions of fractional-order replacements (approximants) of "passive" elements (typical examples of single-purpose filters are given in Ref. 13, Ref. 27-30), there are also methods how to design directly two-port systems (filters in many cases ${ }^{17,18}$ for example) without fractional-order passive elements or their active replacements ${ }^{31-35}$. Some of these works relevant for purposes of this paper are summarized in the following Table 1. Almost all of these circuits are designed for operation in low-frequency bands (up to units or tens of kHz). Except solutions presented in Ref. 34, key features, like reconfigurability of the transfer function, control of pole frequency as well as control of the order of the filter are not present in frame of one designed structure, and these solutions are not providing this mutually independent and electronical type of control at the same time.

This work focuses on the design of fractional-order filter without fractional-order passive elements or their active replacements. Filter provides electronical reconfigurability between fractional-order low-pass filter (FLPF) and fractional-order high-pass filter (FHPF). Pole frequency and also order of the filter are electronically controlled by parameters and coefficients of the filter in both configurations (FLPF and FHPF). Moreover, type of the fractional-order approximation can be also controlled electronically, because all relevant parameters of integer-order transfer function can be controlled electronically. Design is supported not only by simulations, but also by experimental 
laboratory measurements. Our secondary goal was also to compare two particular and most frequently used types of fractional-order approximations as described below.

The text is organized as follows. After introductory part explaining our motivation and providing state of the art, brief overview about relevant active elements is given. Next chapter focuses on details about two common approximations and the design of the FLF topology suitable for fulfilling requirements on electronically controllable and reconfigurable fractional-order filter that is presented together with numerical design in chapter 4. Chapter 5 includes comparison of simulation and measurement results for several scenarios. This chapter gives very complex overview of behavior of the filter under particular circumstances. The last chapter summarizes the most significant findings of this paper.

\section{Active Elements}

The designed filter, presented in the following chapter contains two basic types of controllable active elements. First one is well-known Operational Transconductance Amplifier (OTA) ${ }^{36}$ with current outputs (Fig. 1). Second one is the single-input Adjustable Current Amplifier ${ }^{37}$ (with adjustable current gain) also with several current outputs (Fig. 2).

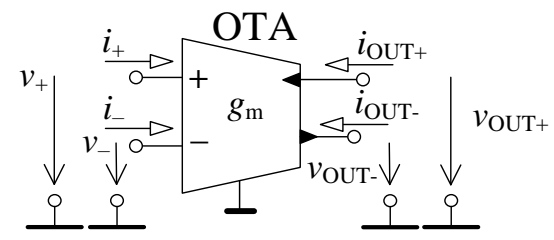

Fig. 1. Operational Transconductance Amplifier (OTA) schematic symbol (dual-output version).

Standard operation of OTA in dual-output configuration as shown in Fig. 1 is described by these straightforward equations:

$$
i_{\text {OUT+ }}=-i_{\text {OUT- }}=g_{m}\left(v_{+}-v_{-}\right) .
$$

Note that transconductance parameter $\left(g_{\mathrm{m}}\right)$ is usually controlled by external DC current and therefore OTA can be considered as simple electronically controllable active element.

Normal operation of ACA is also very simple

$$
i_{\text {OUT+ }}=-i_{\text {OUT }-}=B \cdot i_{I N} .
$$

Current gain $(B)$ is also usually controlled externally, in many cases by DC voltage (referred to as $V_{\text {SET_B }}$ in the following Fig. 2). 
Reconfigurable Fractional-Order Filter 5

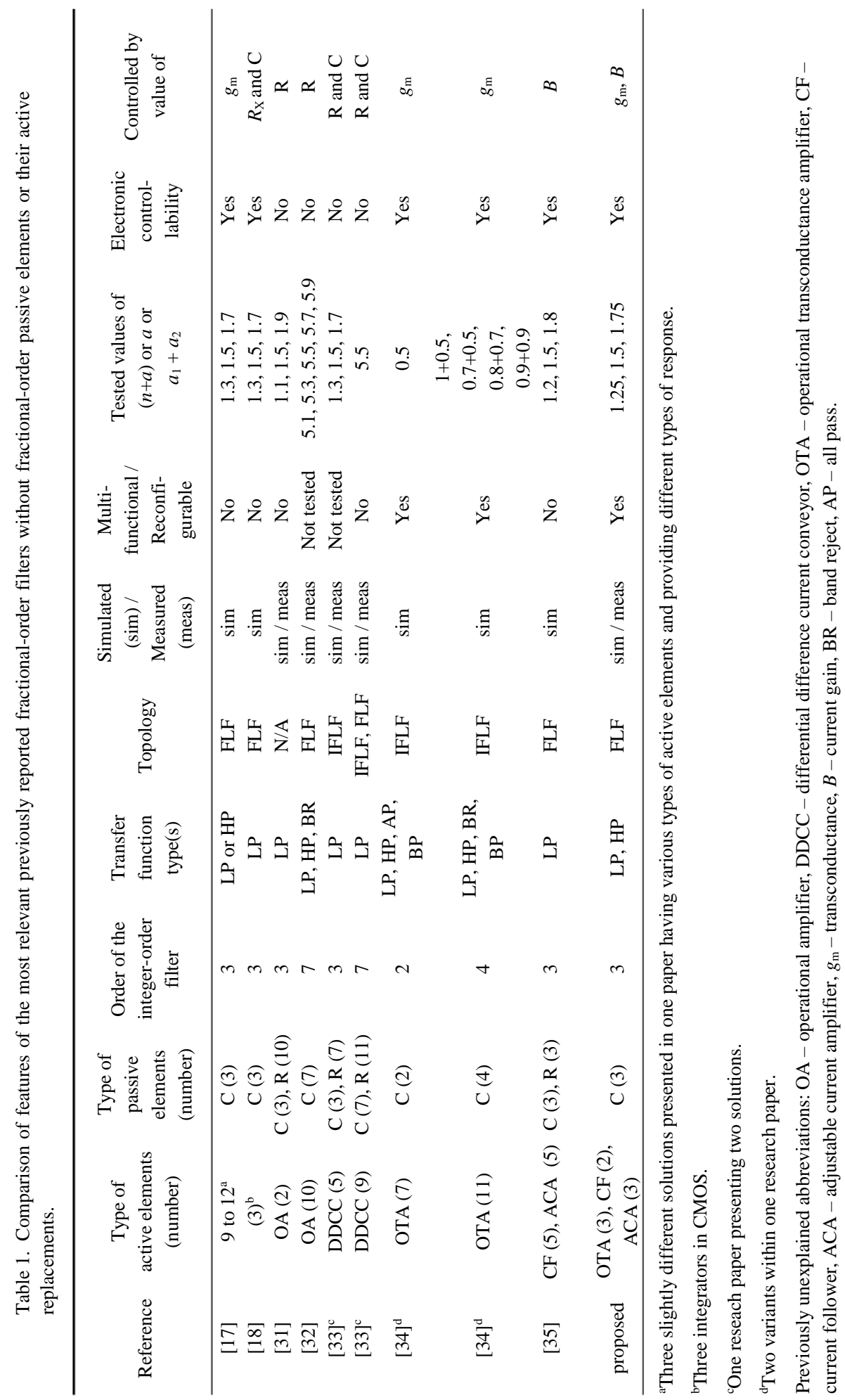




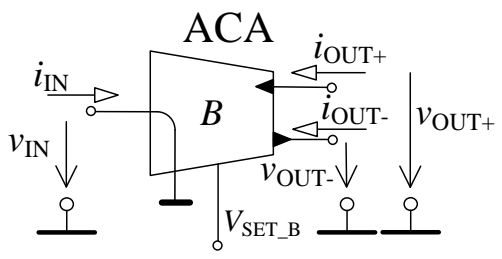

Fig. 2. Adjustable Current Amplifier (ACA) schematic symbol (dual-output version).

Note that for current gain fixed to 1 or -1 , this element is frequently referred to as Current Follower (CF) in case of having single output. If there are two current outputs, element is known as Dual-Output CF (DO-CF) ${ }^{37}$, usually with two opposite polarities of output currents having same magnitude value. Description of the DO-CF element is because of its simplicity omitted in this paper. However, it should be noted that two DO-CF-s are required in the design of the reconfigurable fractional-order filter.

\section{Proposal of the reconfigurable fractional-order filter}

This chapter describes design procedure of the reconfigurable fractional-order filter. First subsection is about design of FLPF, second about FHPF and third part is about its linking into one reconfigurable solution.

\subsection{Butterworth approximation of the fractional-order low-pass filter}

Design procedure of the fractional-order low-pass filter (FLPF) having order of $(1+a)$ was precisely described in Ref. 19 and also Ref. 17. Starting transfer function is in the following form:

$$
K_{1+a}^{L P}(s)=\frac{K_{1}}{s^{1+a}+s^{a} K_{3}+K_{2}} .
$$

where from Ref. 17:

$$
\begin{aligned}
& K_{1}=1, \\
& K_{2}=0.2937 a+0.71216, \\
& K_{3}=1.068 a^{2}+0.161 a+0.3324 .
\end{aligned}
$$

Coefficients $K_{X}$, where $X=1,2,3$ influence directly the shape of the obtained transfer characteristic. Note that the values of $K_{X}$ are dependent on the parameter $a$, i.e. on the order of the filter. Second-order approximation of $\boldsymbol{s}^{a}$ term from eq. 3 is given by:

$$
s^{a}=\frac{a_{0} s^{2}+a_{1} s+a_{2}}{a_{2} s^{2}+a_{1} s+a_{0}} .
$$


There are several ways how to approximate coefficients $a_{0}, a_{1}$ and $a_{2}$ from eq. 5 and two of them are going to be compared within this paper. First set of coefficients can be calculated as follows ${ }^{32}$ :

$$
\begin{aligned}
& a_{0}=2(1+a) \\
& a_{1}=5-a^{2} \\
& a_{2}=2(1-a) .
\end{aligned}
$$

Second approximation ${ }^{19}$ is defined by

$$
\begin{aligned}
& a_{0}=a^{2}+3 a+2, \\
& a_{1}=8-2 a^{2}, \\
& a_{2}=a^{2}-3 a+2 .
\end{aligned}
$$

Note that these approximations are going to be referred to as $1^{\text {st }}$ and $2^{\text {nd }}$ approximation in the rest of the text.

The following standard 3rd-order transfer function will be used to emulate FLPF with Butterworth approximation of order $(1+a)$ [17]:

$$
K_{1+a}^{L P}(s) \cong \frac{K_{1}}{a_{0}} \frac{s^{2} a_{2}+s a_{1}+a_{0}}{s^{3}+s^{2} b_{2}+s b_{1}+b_{0}} .
$$

Formulas for $a_{X}$ coefficients are shown above (two possible approximations), $b_{X}$ coefficients (where $X=0,1,2$ ) are taken from Ref. 19:

$$
\begin{aligned}
& b_{0}=\frac{a_{0} K_{2}+a_{2} K_{3}}{a_{0}}, \\
& b_{1}=\frac{a_{1}\left(K_{2}+K_{3}\right)+a_{2}}{a_{0}}, \\
& b_{2}=\frac{a_{1}+a_{0} K_{3}+a_{2} K_{2}}{a_{0}} .
\end{aligned}
$$

Again, it is worth mentioning that these coefficients are all dependent on parameter $a$. One of possible ways how to implement $3^{\text {rd }}$-order transfer function is to use follow the leader (FLF) filtering topology. Fig. 3 shows the possible block diagram ${ }^{48}$, consisting in our case of three inverting integrators, three feedback loops and three forward signal paths. Note that this topology is going to be used for the filter design below. General transfer function of this topology can be derived directly from Fig. 3 and it is 


$$
K(\boldsymbol{s})=\frac{\boldsymbol{I}_{\text {OUT }}}{\boldsymbol{I}_{I N}}=\frac{\boldsymbol{s}^{2} \frac{G_{1}}{\tau_{1}}+\boldsymbol{s} \frac{G_{2}}{\tau_{1} \tau_{2}}+\frac{G_{3}}{\tau_{1} \tau_{2} \tau_{3}}}{\boldsymbol{s}^{3}+\boldsymbol{s}^{2} \frac{1}{\tau_{1}}+\boldsymbol{s} \frac{1}{\tau_{1} \tau_{2}}+\frac{1}{\tau_{1} \tau_{2} \tau_{3}}}
$$

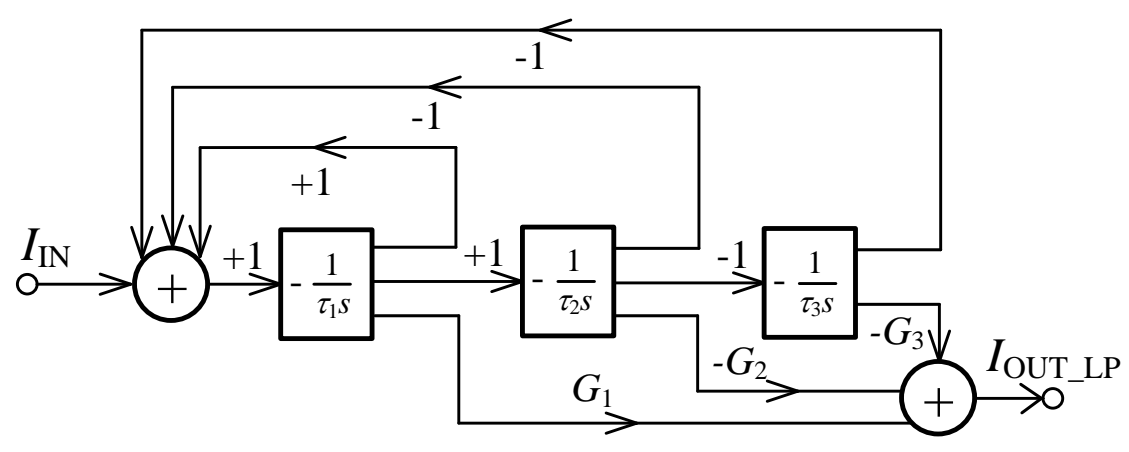

Fig. 3. Block diagram of a FLF (follow-the-leader feedback) topology ${ }^{48}$ used for approximation of the FLPF (fractional-order low-pass filter) of $(1+a)$ order.

Set of equations how to obtain $\tau_{X}$ and $G_{X}$ (when $X=1,2,3$ ) in eq. 10 from $a_{\mathrm{X}}$ and $b_{\mathrm{X}}$ coefficients (where $X=1,2,3$ ) are obvious when comparing eq. 10 and eq. 8 .

\subsection{Butterworth approximation of the fractional-order high-pass filter}

Similarly to FLPF, design procedure of the fractional-order high-pass filter (FHPF) having order of $(1+a)$ was also precisely described in Ref. 17. Starting transfer function is in the following form:

$$
K_{1+a}^{H P}(s)=\frac{K_{1} s^{1+a}}{K_{2} s^{1+a}+K_{3} s^{a}+1}
$$

where coefficients $K_{X},(X=1,2,3)$, are defined exactly the same way as in case of FLPF, i.e. by eq. 4. Similarly, eqs. 5 to 7 also apply for FHPF design procedure.

Based on this, the following standard 3rd-order transfer function will be used to emulate FHPF with Butterworth approximation of order $(1+a)^{17}$ :

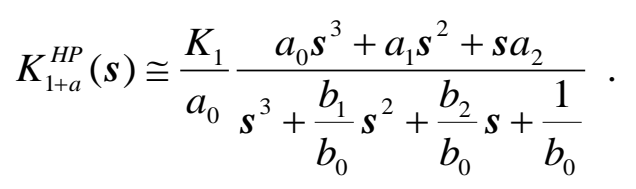

Formulas for $a_{\mathrm{X}}$ coefficients are shown above in two possible approximations (eq. 6, eq. 7), $b_{\mathrm{X}}$ coefficients are equal to eq. 9 shown above. 
In this particular case, 3rd-order transfer function based of FLF type of topology can be also used. Fig. 4 shows the particular block diagram ${ }^{49}$, consisting of inverting integrators, supplemented by three feedback loops and three forward signal paths. Transfer function of this general topology is

$$
K(s)=\frac{\boldsymbol{I}_{O U T}}{\boldsymbol{I}_{I N}}=\frac{s^{3} G_{1}+s^{2} \frac{G_{2}}{\tau_{1}}+s \frac{G_{3}}{\tau_{1} \tau_{2}}}{s^{3}+s^{2} \frac{1}{\tau_{1}}+s \frac{1}{\tau_{1} \tau_{2}}+\frac{1}{\tau_{1} \tau_{2} \tau_{3}}} .
$$

Similarly to FLPF, equations how to obtain $\tau_{\mathrm{X}}$ and $G_{\mathrm{X}}$ from $a_{\mathrm{X}}$ and $b_{\mathrm{X}}$ coefficients are obvious when comparing eq. 13 and eq. 12 .

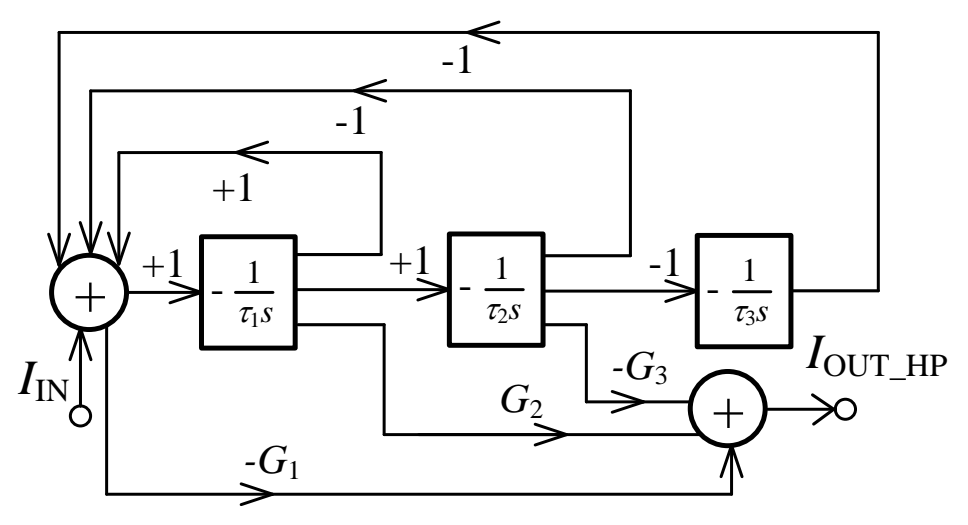

Fig. 4. Block diagram of a 3rd-order FLF (follow-the-leader feedback) topology ${ }^{49}$ used for approximation of the FHPF (fractional-order high-pass filter) of $(1+a)$ order.

\subsection{Linking of FLPF and FHPF topology into one structure}

When we compare Fig. 3 and Fig. 4, it is clear that these topologies are very similar. Therefore, these topologies could be linked together and actually made by one general FLF structure with just two additional switches referred to as "LP" and "HP" in the following Fig. 5 showing final form of the block diagram of designed reconfigurable fractional-order filter. These switches could be implemented easily by additional transistor-level structures or additional ACA active elements providing zero or unity gain in particular forward branch of this current-mode circuit. 


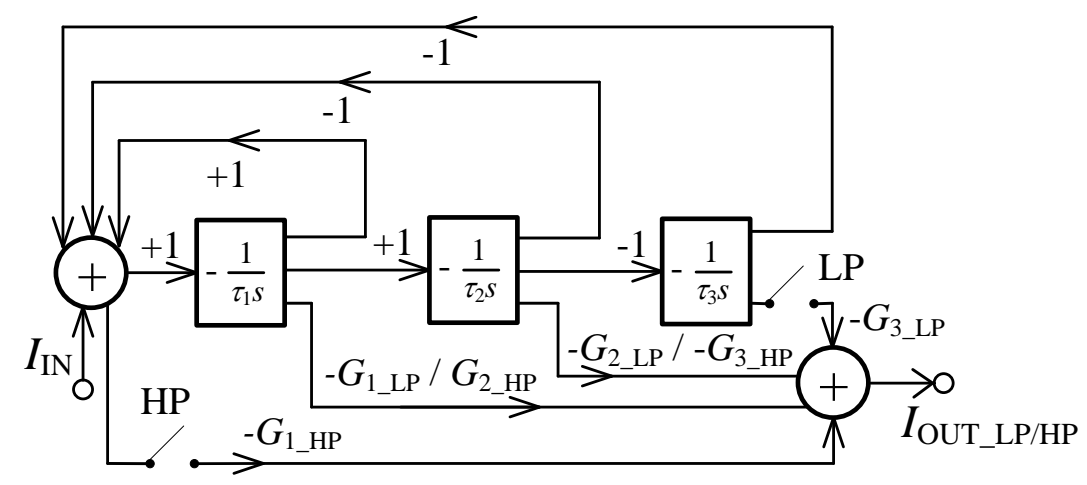

Fig. 5. Generalized block diagram of a 3rd-order FLF (follow-the-leader feedback) topology used for approximation of both the FLPF and FHPF of $(1+a)$ order.

Designed reconfigurable filter with active elements introduced in chapter 2 and based on generalized FLF block topology (Fig. 5) is shown in Fig. 6. It is obvious that there are three OTA amplifiers with $g_{\mathrm{m} 1}, g_{\mathrm{m} 2}$ and $g_{\mathrm{m} 3}$ controllable parameters, three ACA elements having $B_{1}, B_{2}$ and $B_{3}$ gains and two supplementary DO-CF-s. One of them is near input of the filter, the second one is not shown directly in Fig. 6. However, it forms part of DO-ACA1, because this element is actually built by ACA and DO-CF element as will be described below. There are also three capacitors, in each case at the input high-impedance terminal of OTA element, in order to form inverting lossless integrator as shown in generalized block structure (Fig. 5).

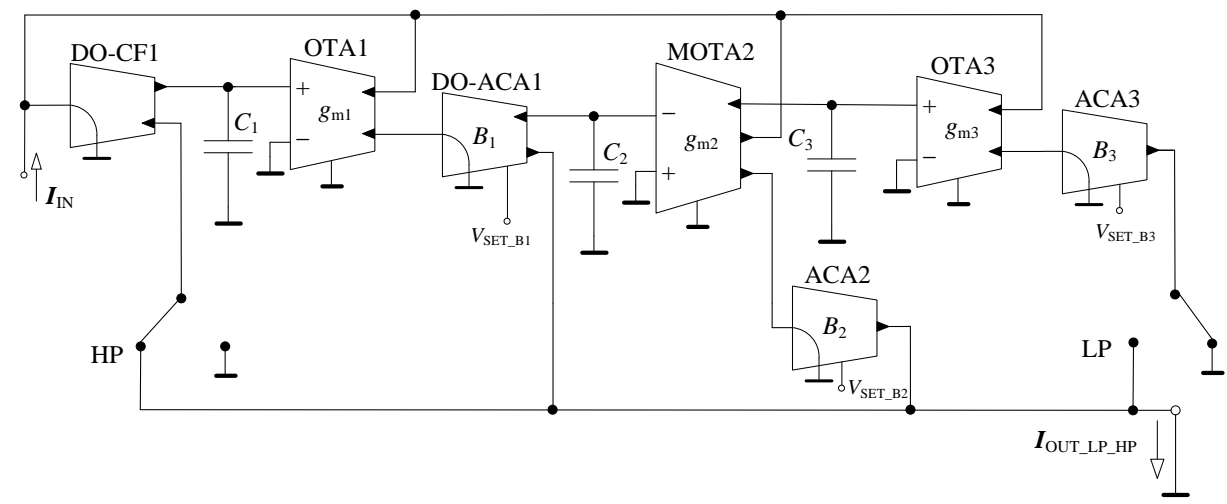

Fig. 6. Particular solution of reconfigurable 3rd-order FLF (follow-the-leader feedback) topology used for approximation of both the FLPF and FHPF of $(1+a)$ order. Currently in HP response configuration shown as an example.

Generally, transfer function of filter from Fig. 6 is: 


$$
K_{\text {general }}(\boldsymbol{s})=\frac{\boldsymbol{I}_{\text {OUT_LP_HP }}}{\boldsymbol{I}_{I N}}=\frac{N_{L P_{-} o r_{-} H P}(\boldsymbol{s})}{D_{\text {general }}(\boldsymbol{s})}
$$

Denominator of this transfer function is equal to:

$$
D_{\text {general }}(s)=s^{3}+s^{2} \frac{g_{m 1}}{C_{1}}+s \frac{g_{m 1} g_{m 2} B_{1}}{C_{1} C_{2}}+\frac{g_{m 1} g_{m 2} g_{m 3} B_{1}}{C_{1} C_{2} C_{3}}
$$

If "LP" switch is "on" and "HP" switch is "off", FLPF response is configured from the general filtering structure and nominator is as follows:

$$
N_{L P}(\boldsymbol{s})=-\boldsymbol{s}^{2} \frac{g_{m 1} B_{1}}{C_{1}}-\boldsymbol{s} \frac{g_{m 1} g_{m 2} B_{1} B_{2}}{C_{1} C_{2}}-\frac{g_{m 1} g_{m 2} g_{m 3} B_{1} B_{3}}{C_{1} C_{2} C_{3}}
$$

If "LP" switch is "off" and "HP" switch is "on", FHPF response is configured and nominator is in the following form:

$$
N_{H P}(s)=-s^{3}-s^{2} \frac{g_{m 1} B_{1}}{C_{1}}-s \frac{g_{m 1} g_{m 2} B_{1} B_{2}}{C_{1} C_{2}}
$$

It is obvious that both eq. 16 and eq. 17 together with eq. 15 represent inverting form of the transfer function and reconfiguration of the type of transfer function is available by control of "LP" and "HP" switches. Particular meaning of quantities or variables used in eqs. 15,16 and 17 is obvious from Fig. 6. As already mentioned, several parameters can be controlled electronically (all values except values of $C_{1}, C_{2}$ and $C_{3}$ ), which is beneficial feature for future change of the filter order and also the control of the pole frequency. This is going to be demonstrated in the following sections.

\section{Numerical design of the reconfigurable filter}

\subsection{FLPF mode of reconfigurable filter}

In order to verify the design, values of all components have been calculated based on eqs. 3 to 10 and eqs. 14 to 16 . Chosen parameters of the filter are: starting pole frequencies determining the pass-band: $f_{0 \_\mathrm{LP}}=\omega_{0} / 2 \pi=100 \mathrm{kHz}$, values of capacitors: $C_{1}=1.8 \mathrm{nF}, C_{2}$ $=470 \mathrm{pF}$ and $C_{3}=18 \mathrm{nF}$. The rest of the parameters is dependent on chosen type of approximation of $\boldsymbol{s}^{a}$ term, i.e. eqs. 6 and 7 . Calculated values for $1^{\text {st }} / 2^{\text {nd }}$ approximation are summarized in Table 2. 
Table 2. Numerical values of relevant parameters of the filter in FLPF configuration for $f_{0 \_L P}=100 \mathrm{kHz}$. Both $1^{\text {st }}$ and $2^{\text {nd }}$ approximation $\left(1^{\text {st }} / 2^{\text {nd }}\right.$ value if applicable $)$.

\begin{tabular}{cccc}
\hline & \multicolumn{3}{c}{ Order of the filter } \\
\hline Particular parameter & 1.25 & 1.5 & 1.75 \\
\hline$C_{1}[\mathrm{nF}]$ & 1.8 & 1.8 & 1.8 \\
$C_{2}[\mathrm{pF}]$ & 470 & 470 & 470 \\
$C_{3}[\mathrm{nF}]$ & 18 & 18 & 18 \\
$R_{1}=1 / g_{\mathrm{m} 1}[\Omega]$ & $306 / 245$ & $347 / 310$ & $360 / 348$ \\
$R_{2}=1 / g_{\mathrm{m} 2}[\Omega]$ & $673 / 406$ & $408 / 207$ & $182 / 76$ \\
$R_{3}=1 / g_{\mathrm{m} 3}[\Omega]$ & $254 / 348$ & $226 / 291$ & $217 / 256$ \\
$B_{1}[-]$ & $0.208 / 0.129$ & $0.131 / 0.075$ & $0.058 / 0.026$ \\
$B_{2}[-]$ & $0.654 / 0.719$ & $0.572 / 0.610$ & $0.476 / 0.492$ \\
$B_{3}[-]$ & $0.953 / 1.009$ & $0.921 / 1.005$ & $0.923 / 0.999$ \\
\hline
\end{tabular}

\subsection{FHPF mode of reconfigurable filter}

Based on eqs. 11, 4 to 7, 9 and eqs. 13 to 15 and 17, and similarly to the FLPF design described in the previous chapter, values of all components have been calculated. Chosen parameters of the filter are exactly the same as in case of FLPF: starting pole frequencies determining the pass-band: $f_{0 \_\mathrm{LP}}=\omega_{0} / 2 \pi=100 \mathrm{kHz}$, values of capacitors: $C_{1}=1.8 \mathrm{nF}, C_{2}$ $=470 \mathrm{pF}$ and $C_{3}=18 \mathrm{nF}$. This allows reconfiguration of the filter between FLPF and FHPF. The rest of the parameters is again dependent on chosen type of approximation of $\boldsymbol{s}^{a}$ term, i.e. eqs. 6 and 7. Calculated values for $1^{\text {st }} / 2^{\text {nd }}$ approximation are summarized in Table 3. When we compare values from Table 2 and Table 3 , it is obvious that only electronically controlled parameters have to be changed during tuning of order of the filter or type of the approximation. Of course, the choice of transfer function type is done by switches "LP" and "HP", as already mentioned.

Table 3. Numerical values of relevant parameters of the filter in FHPF configuration for $f_{0 \_L P}=100 \mathrm{kHz}$. Both $1^{\text {st }}$ and $2^{\text {nd }}$ approximation $\left(1^{\text {st }} / 2^{\text {nd }}\right.$ value if applicable $)$.

\begin{tabular}{cccc}
\hline & \multicolumn{3}{c}{ Order of the filter } \\
\hline Particular parameter & 1.25 & 1.5 & 1.75 \\
\hline$C_{1}[\mathrm{nF}]$ & & 1.8 & \\
$C_{2}[\mathrm{pF}]$ & 470 \\
$C_{3}[\mathrm{nF}]$ & 18 & \\
$R_{1}=1 / g_{\mathrm{m} 1}[\Omega]$ & $307 / 225$ & $347 / 268$ & $360 / 305$ \\
$R_{2}=1 / g_{\mathrm{m} 2}[\Omega]$ & $2432 / 2605$ & $2283 / 2363$ & $1894 / 1904$ \\
$R_{3}=1 / g_{\mathrm{m} 3}[\Omega]$ & $255 / 319$ & $225 / 252$ & $217 / 225$ \\
$B_{1}[-]$ & $0.686 / 0.712$ & $0.621 / 0.607$ & $0.516 / 0.493$ \\
$B_{2}[-]$ & $0.218 / 0.128$ & $0.142 / 0.070$ & $0.063 / 0.026$ \\
\hline
\end{tabular}




\subsection{Frequency tuning of the filter}

The proposed fractional-order filter provides pole frequency control by simultaneous change of values of transconductances without disturbing quality factor and order of the filter. Chosen parameters of the capacitors and current gains are the same in case FLPF and FHPF, respectively. Order of the filter was 1.5 in each of these cases. Values of capacitors are exactly the same as in the previous case: $C_{1}=1.8 \mathrm{nF}, C_{2}=470 \mathrm{pF}$ and $C_{3}=18 \mathrm{nF}$. Calculated values of the resistors representing $1 / g_{m}$-s of the FLPF for three selected values of the pole frequency are summarized in Table 4 . Table 5 summarizes numerical values of the $1 / g_{m}$-s for FHPF in case of the same set of pole frequencies. Note that in these tables are stated values of $1 / g_{m}$-s for $1^{\text {st }} / 2^{\text {nd }}$ approximation.

Table 4. Numerical values of relevant parameters of the filter in FLPF configuration for constant order of the filter 1.5 . Both $1^{\text {st }}$ and $2^{\text {nd }}$ approximation $\left(1^{\text {st }} / 2^{\text {nd }}\right.$ value $)$.

\begin{tabular}{cccc}
\hline & \multicolumn{3}{c}{ Pole frequency $[\mathrm{kHz}]$} \\
\hline Particular parameter & 33 & 100 & 300 \\
\hline$R_{1}=1 / g_{\mathrm{m} 1}[\Omega]$ & $1041 / 931$ & $347 / 310$ & $116 / 103$ \\
$R_{2}=1 / g_{\mathrm{m} 2}[\Omega]$ & $1224 / 620$ & $408 / 207$ & $136 / 69$ \\
$R_{3}=1 / g_{\mathrm{m} 3}[\Omega]$ & $678 / 875$ & $226 / 291$ & $75 / 97$ \\
\hline
\end{tabular}

Table 5. Numerical values of relevant parameters of the filter in FHPF configuration for constant order of the filter 1.5. ( $\left(1^{\mathrm{st}} / 2^{\text {nd }}\right.$ approximation $)$.

\begin{tabular}{cccc}
\hline & \multicolumn{3}{c}{ Pole frequency $[\mathrm{kHz}]$} \\
\hline Particular parameter & 33 & 100 & 300 \\
\hline$R_{1}=1 / g_{\mathrm{m} 1}[\Omega]$ & $1041 / 813$ & $347 / 268$ & $116 / 89$ \\
$R_{2}=1 / g_{\mathrm{m} 2}[\Omega]$ & $6849 / 7161$ & $2283 / 2363$ & $761 / 788$ \\
$R_{3}=1 / g_{\mathrm{m} 3}[\Omega]$ & $675 / 764$ & $225 / 252$ & $75 / 84$ \\
\hline
\end{tabular}

\section{Simulation and experimental results}

To verify the correct function of the proposed fractional-order topology from Fig. 6, the PSpice simulations and also experimental measurement are performed and mutually compared. The PSpice simulations of the filter were performed using behavioral simulation models of the OTA, MOTA, DO-CF and ACA elements which are mentioned in Chapter 2. For experimental measurement, the filter was implemented in PCB (Printed Circuit Board) form corresponding with the behavioral model in PSpice simulator. The OTA and MOTA elements were replaced by UCC_N1B_0520 ${ }^{47}$ chips with discrete external resistors $(R)$ connected to X terminal representing $g_{m}$-S of OTA-s. The UCC_N1B_0520 chip includes one UCC (Universal Current Conveyor) active element and one secondgeneration Current Conveyor (CCII+/-). The DO-CF element providing input current distribution as obvious from Fig. 6, was implemented by CCII+/-. The EL2082 $2^{50}$ chips are 
used for implementation of the ACA elements within the reconfigurable topology. Note that in order to implement dual-output version of ACA (DO-CA1 from the structure shown in Fig. 6), cascade connection of EL2082 and CCII+/- was used in case of both simulation and measurement. The current gain of the EL2082 is controlled by DC voltage in range from 0 to $2.5 \mathrm{~V}$ with gain numerically approximately equal to value of control voltage.

\subsection{Measurement and simulation results for FLPF}

Figure 7 illustrates measurement results (solid lines) of the electronic control of the FLPF order for $1^{\text {st }}$ approximation (eq. 6) in comparison with simulation results (dashed lines). Values of all passive components and gains are summarized in Table 2. From magnitude and phase responses it is obvious that experimental results are in good agreement with simulation results, however the pole frequency from the measurement results is slightly higher in comparison with simulations. This frequency shift can be caused by inaccurate values of the used capacitors and transconductances. The biggest differences can be seen for filter with order 1.75 . This difference is given mainly because value of the $B_{1}$ (see Table 2 ) is relatively small and therefore not enough accurate. Measurement (solid lines) and simulation (dashed lines) results of the FLPF with used approximation from eq. 7 ( $2^{\text {nd }}$ approximation) are compared in Fig. 8. Values of all passive components and gains are also summarized in Table 2. From obtained responses it can be seen that pole frequency is slightly shifted as seen also in the previous graph. The differences between measurement and simulation results of the FLPF with order 1.75 are also caused by small value of parameters, $g_{\mathrm{m} 2}$ and $B_{1}$ particularly.

Note that slope of attenuation of the transfer magnitude, for three selected orders and used $1^{\text {st }}$ approximation, illustrated in Fig. 7, has fractional character only in short frequency range as expected because of the $2^{\text {nd }}$-order approximation of $\boldsymbol{s}^{\mathrm{a}}$, as represented by eq. 5 . Slope of attenuation of the transfer functions of the filter with $2^{\text {nd }}$ approximation (Fig. 8) has fractional character in wider frequency range than filter with $1^{\text {st }}$ approximation. These differences are caused by type of chosen approximation. The frequency range of the fractional character is dependent on chosen value of the filter's order. Note that this applies to all achieved results in this paper. 


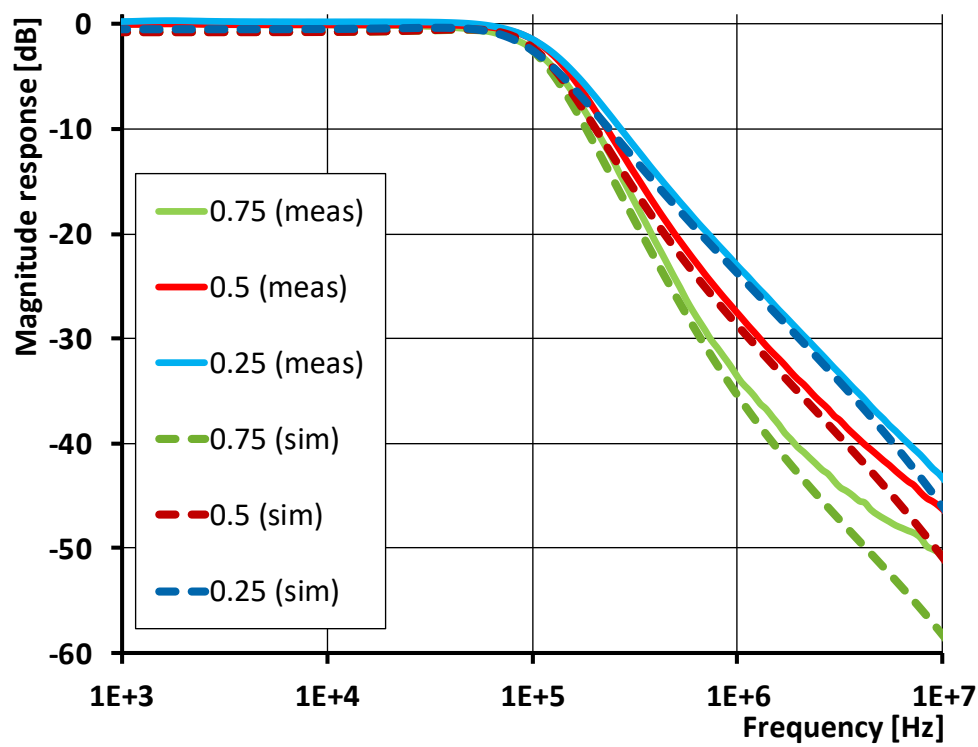

(a)



(b)

Fig. 7. Simulation (dashed lines) and measurement (solid lines) results of the FLPF for $1^{\text {st }}$ approximation: (a) magnitude response, (b) phase response. 


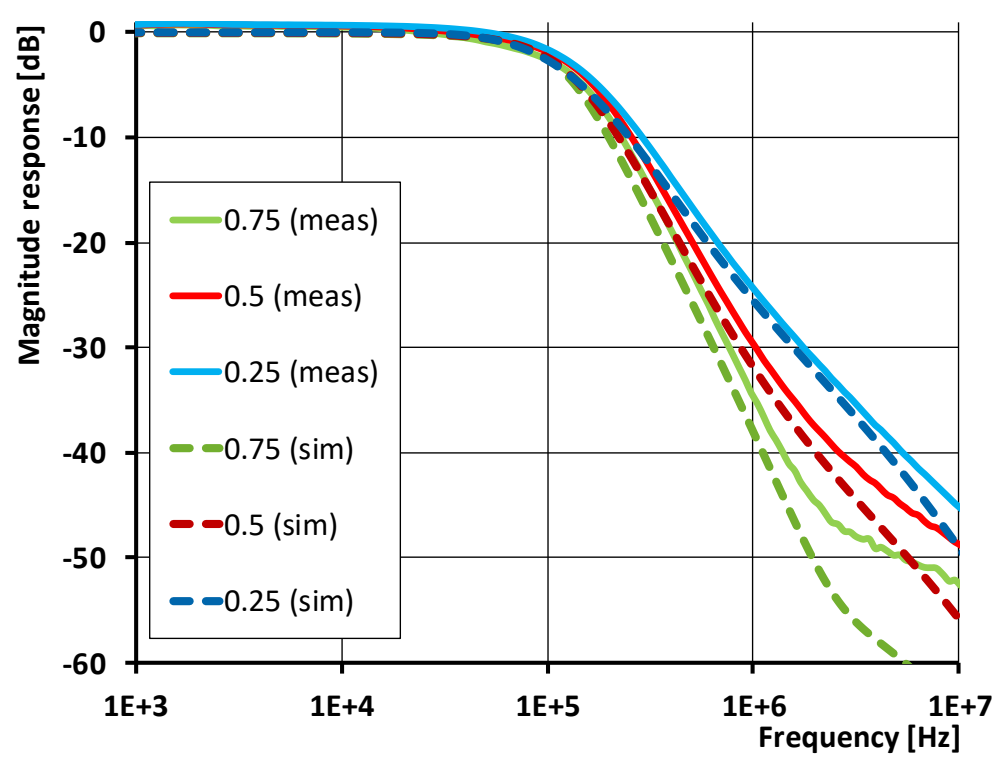

(a)

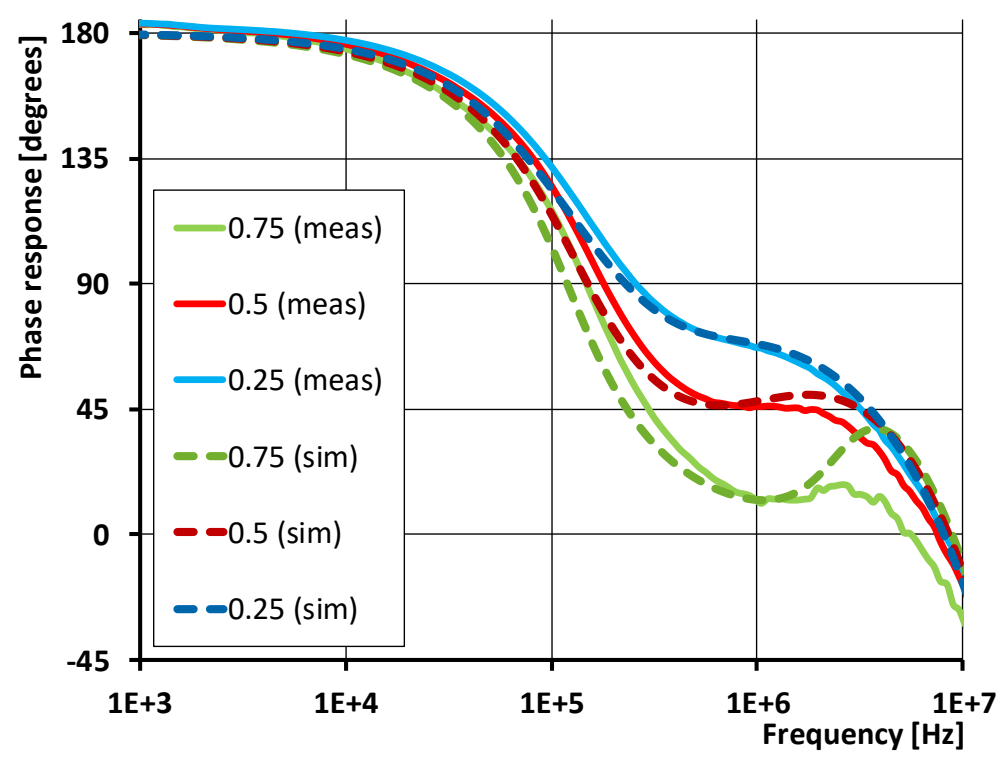

(b)

Fig. 8. Simulation (dashed lines) and measurement (solid lines) results of the FLPF for $2^{\text {nd }}$ approximation: (a) magnitude response, (b) phase response. 


\subsection{Measurement and simulation results for $\mathrm{FHPF}$}

A comparison of the measurement and simulation results in case of electronically controlled order of the FHPF for $1^{\text {st }}$ approximation based on eq. 6 is shown in Fig. 9. The chosen values of the order, when the pole frequency is $100 \mathrm{kHz}$, are the same as at the FLPF, i.e.: 1.25, 1.5 and 1.75. Values of all passive components and gains are summarized in Table 3 shown above.

Figure 10 illustrates magnitude and phase responses of the FHPF for $2^{\text {nd }}$ used approximation from eq. 7. A comparison of the obtained measurement (solid lines) and simulation (dashed lines) results is demonstrated in these graphs for above mentioned values of the order. Again, values of all passive components and gains are summarized in Table 3 shown above.

From magnitude responses in Fig. 9 and Fig. 10 can be seen that obtained measurement results (solid lines) are slightly different in comparison with simulation results (dashed lines). Differences at higher frequencies (around $8 \mathrm{MHz}$ ) are caused by bandwidth limitations of the used active elements and parasitic capacitance of the designed PCB and are not important in these cases. Other differences are given by inaccuracies of the gains and passive elements.

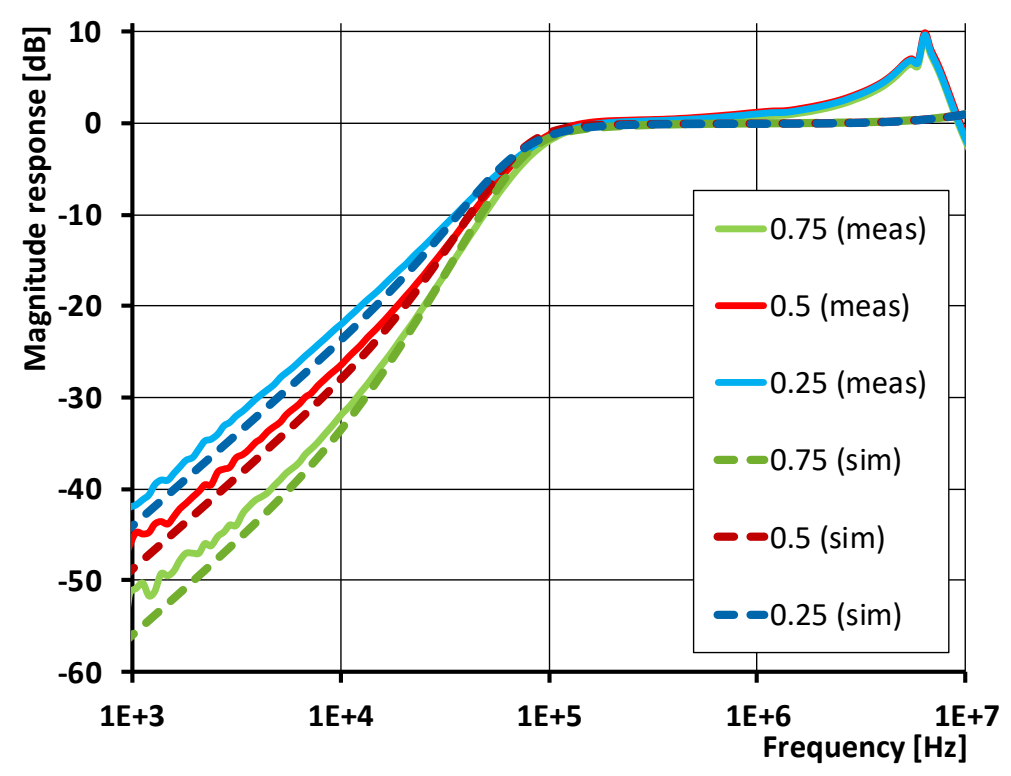

(a) 


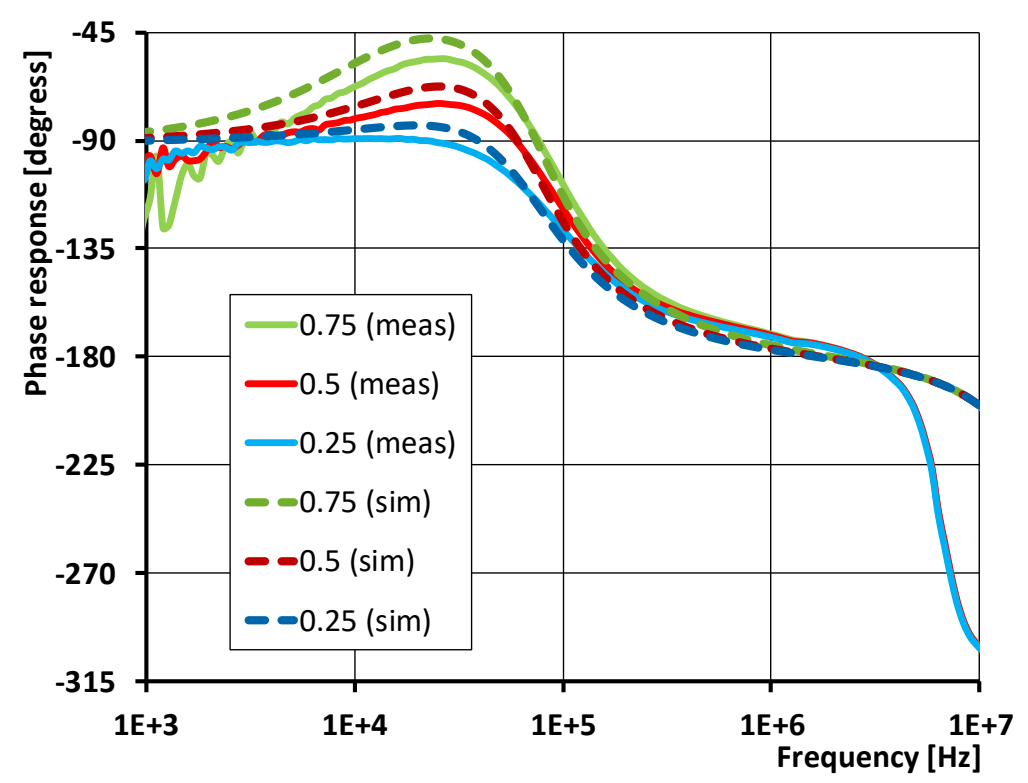

(b)

Fig. 9. Simulation (dashed lines) and measurement (solid lines) results of the FHPF for $1^{\text {st }}$ approximation: (a) magnitude response, (b) phase response.

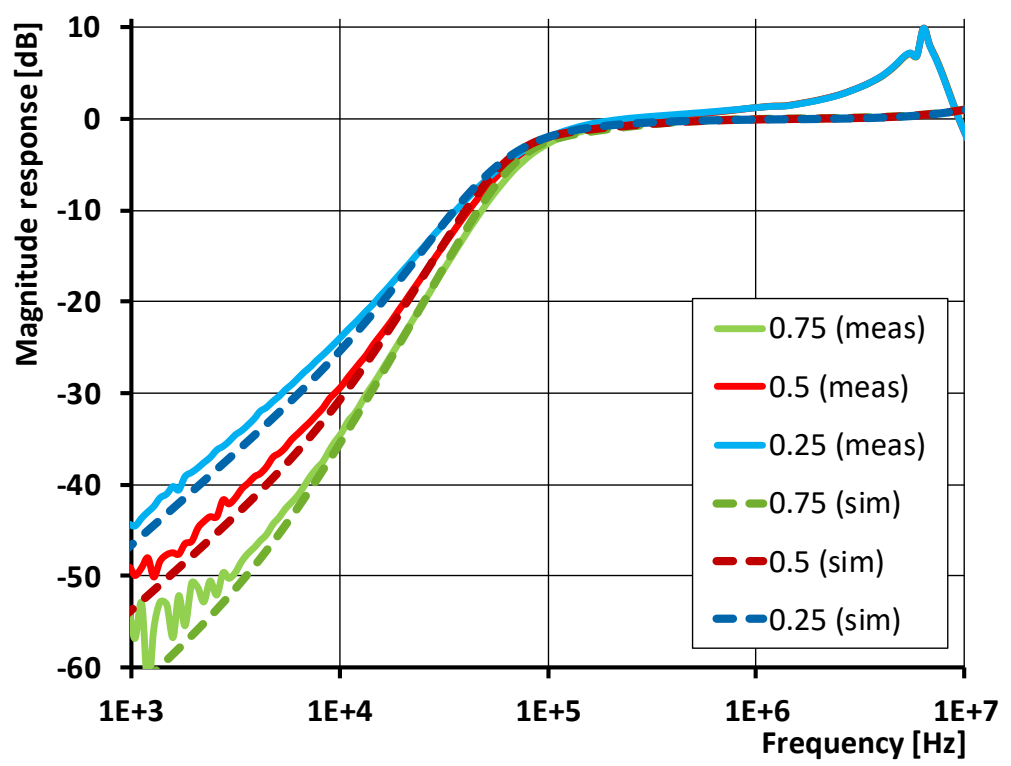

(a) 


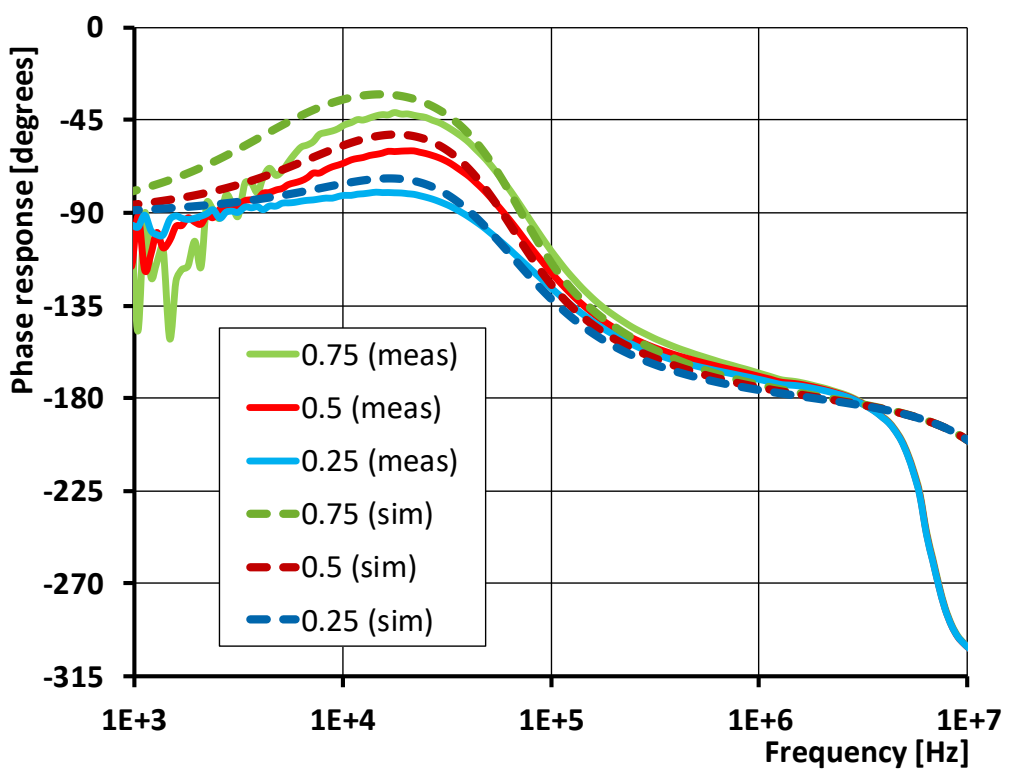

(b)

Fig. 10. Simulation (dashed lines) and measurement (solid lines) results of the FHPF for $2^{\text {nd }}$ approximation: (a) magnitude response, (b) phase response.

\subsection{Control of the frequencies of both the FLPF and FHPF}

Magnitude and phase responses while electronically controlling the pole frequency of the FLPF, for used $2^{\text {nd }}$ approximation as an example, are shown in Fig. 11 (a), (b). Chosen pole frequencies are: 33,100 and $300 \mathrm{kHz}$ and all other parameters are summarized in Table 4. A comparison of the measurement (solid lines) and simulation (dashed lines) results is performed also in this case.

From Fig. 11 (a) it is obvious that measurement and simulation results are very similar. However, results for filter with the pole frequency $f_{0 \_L P}=300 \mathrm{kHz}$ are affected by really small values of the $1 / g_{m}$-s (see Table 4).

Figure 12 (a), (b) illustrates magnitude and phase response of the three selected values of the pole frequency of the FHPF (again the $2^{\text {nd }}$ approximation is used as an example, all parameters are shown in Table 5). From Fig. 12 is obvious that obtained results are also in good agreement with theory. The bandwidth limitations of the used active elements can be seen at higher frequencies. 


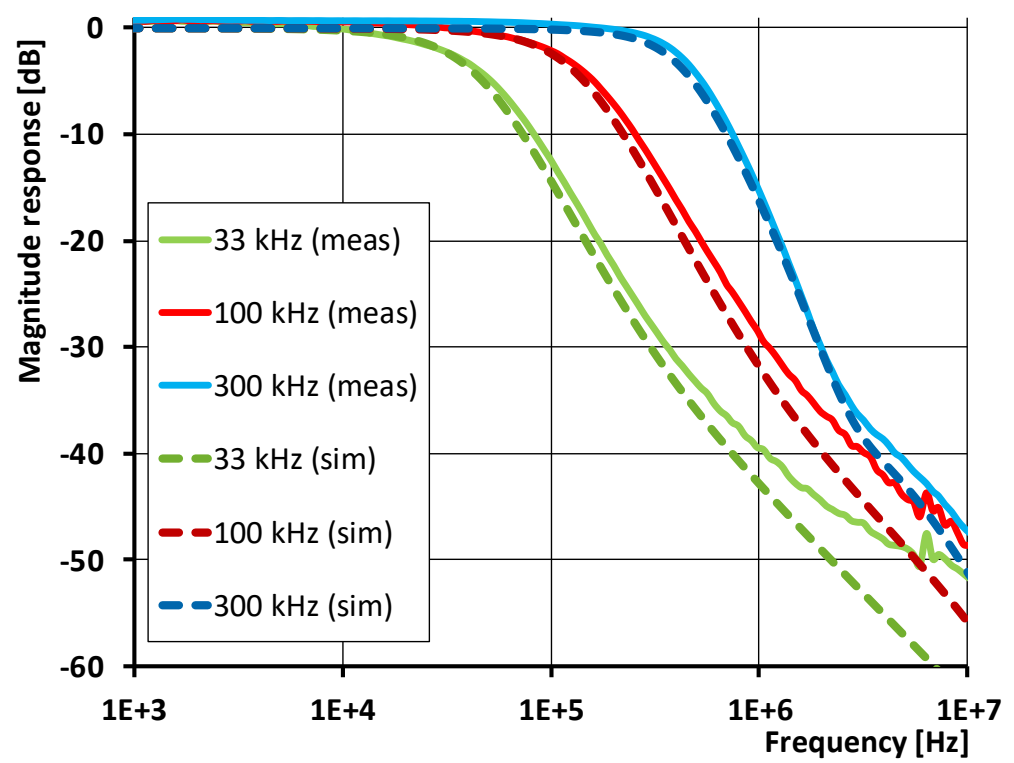

(a)

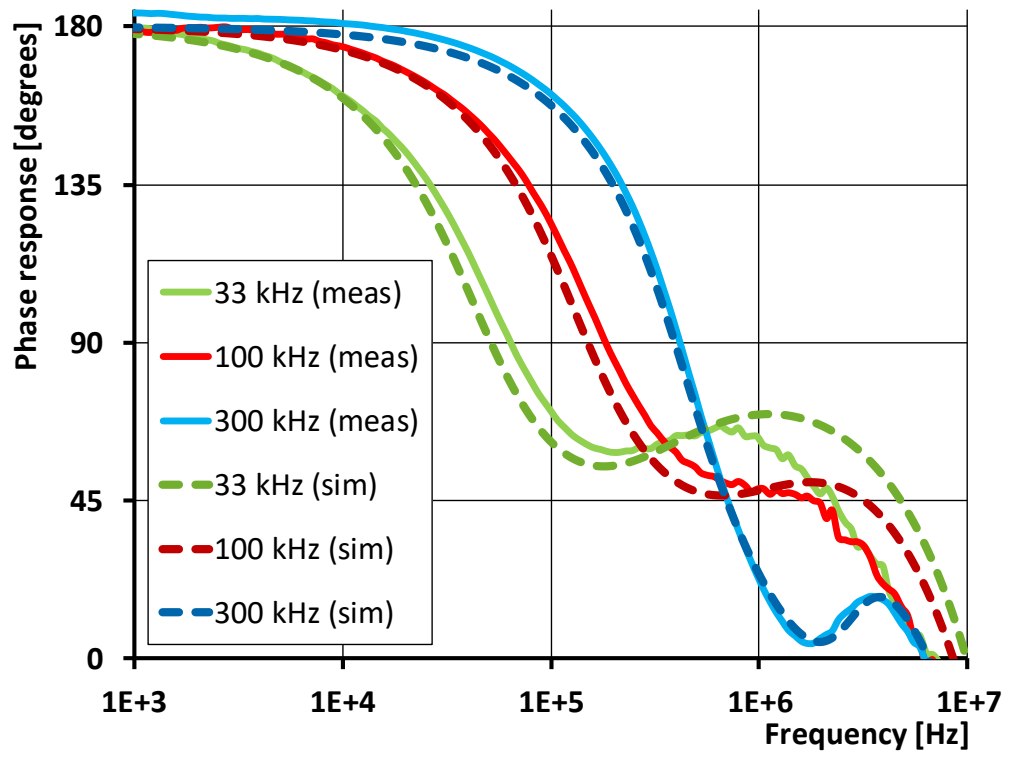

(b)

Fig. 11. Demonstration of the electronic control of the pole frequency of the FLPF for $2^{\text {nd }}$ approximation with constant order equal to 1.5: (a) magnitude response, (b) phase response. 


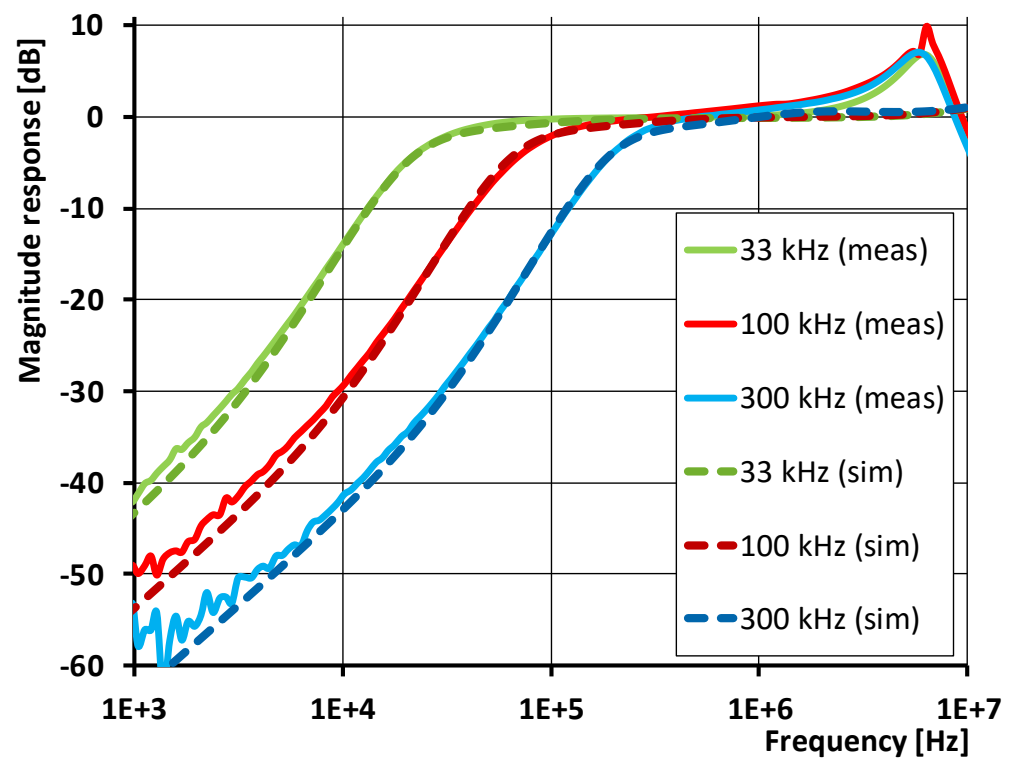

(a)

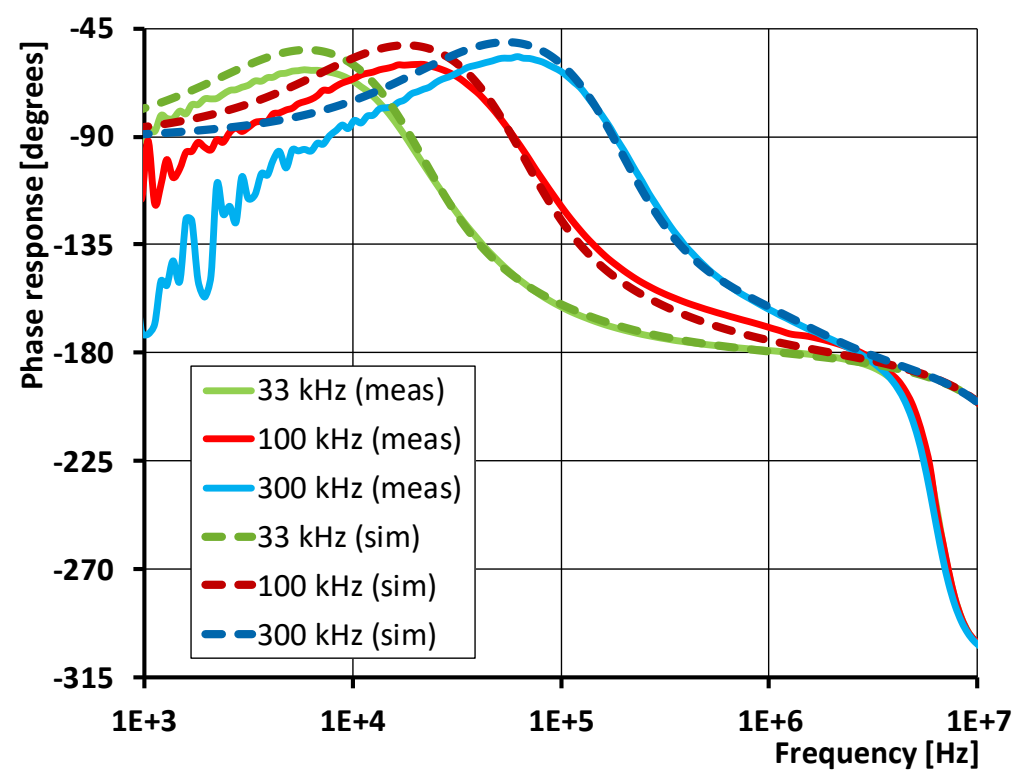

(b)

Fig. 12. Demonstration of the electronic control of the pole frequency of the FHPF for $2^{\text {nd }}$ approximation with constant order 1.5: (a) magnitude response, (b) phase response. 


\subsection{Summarization of the obtained results}

Table 6 and Table 7 summarize obtained values of the slope of attenuation of the transfer function of the FLPF and FHPF for three designed values of the order. A comparison of the values of the slope of attenuation of the filters for $1^{\text {st }}$ and $2^{\text {nd }}$ approximation is made. From obtained experimental results can be seen that values of the slope of attenuation are not far from the theoretical results. FLPF for $1^{\text {st }}$ and $2^{\text {nd }}$ approximation is performing very similarly. Bigger differences are seen between values of the slope of attenuation of the FHPF for $1^{\text {st }}$ and $2^{\text {nd }}$ approximation.

The obtained theoretical, simulated and measured results of the pole frequency while tuning of the FLPF and FHPF, for chosen $2^{\text {nd }}$ approximation, are compared in Table 8 and Table 9. From obtained values of the pole frequency of the FLPF (Table 8) can be seen that measurement results are very close to the theory. The biggest difference between theoretical and measured values of the pole frequency of the FLPF is obvious for the highest configured pole frequency $(300 \mathrm{kHz})$. It is caused by relative small value of the resistors $R_{1}, R_{2}$ and $R_{3}$. From measurement results of the frequency tuning of the FHPF (Table 9 ) is obvious that obtained values of the pole frequency are also very close to the theoretical assumptions.

Table 6. Comparison of the theoretical, simulated and measured values of slope of attenuation of the filter in FLPF configuration for pole frequency of the filter $100 \mathrm{kHz}$. Both $1^{\text {st }}$ and $2^{\text {nd }}$ approximation $\left(1^{\text {st }} / 2^{\text {nd }}\right.$ value if applicable $)$.

\begin{tabular}{cccc}
\hline & \multicolumn{3}{c}{ Order } \\
\hline Slope of attenuation $[\mathrm{dB} / \mathrm{dec}]$ & 1.25 & 1.5 & 1.75 \\
\hline Theoretical & 25.0 & 30.0 & 35.0 \\
Simulated & $22.7 / 24.2$ & $29.8 / 31.6$ & $36.3 / 36.9$ \\
Measured & $23.9 / 24.2$ & $30.0 / 29.8$ & $35.3 / 35.2$ \\
\hline
\end{tabular}

Table 7. Comparison of the theoretical, simulated and measured values of slope of attenuation of the filter in FHPF configuration for pole frequency of the filter $100 \mathrm{kHz}$. Both $1^{\text {st }}$ and $2^{\text {nd }}$ approximation $\left(1^{\text {st }} / 2^{\text {nd }}\right.$ value if applicable $)$.

\begin{tabular}{cccc}
\hline & \multicolumn{3}{c}{ Order } \\
\hline Slope of attenuation $[\mathrm{dB} / \mathrm{dec}]$ & 1.25 & 1.5 & 1.75 \\
\hline Theoretical & 25.0 & 30.0 & 35.0 \\
Simulated & $25.7 / 24.3$ & $31.5 / 31.0$ & $36.7 / 35.6$ \\
Measured & $22.8 / 24.7$ & $29.5 / 31.5$ & $34.9 / 35.9$ \\
\hline
\end{tabular}


Table 8. Comparison of the theoretical, simulated and measured values of the pole frequency of the filter in FLPF configuration for constant order of the filter 1.5. The $2^{\text {nd }}$ approximation is used.

\begin{tabular}{cccc}
\hline & \multicolumn{3}{c}{ Pole frequency $[\mathrm{kHz}]$} \\
\hline Theoretical & 33.0 & 100.0 & 300.0 \\
Simulated & 35.9 & 112.1 & 383.5 \\
Measured & 33.1 & 108.0 & 398.1 \\
\hline
\end{tabular}

Table 9. Comparison of the theoretical, simulated and measured values of the pole frequency of the filter in FHPF configuration for constant order of the filter 1.5. The $2^{\text {nd }}$ approximation is used.

\begin{tabular}{cccc}
\hline & \multicolumn{3}{c}{ Pole frequency $[\mathrm{kHz}]$} \\
\hline Theoretical & 33.0 & 100.0 & 300.0 \\
Simulated & 27.3 & 81.4 & 227.2 \\
Measured & 27.0 & 95.5 & 289.8 \\
\hline
\end{tabular}

\section{Conclusion}

Reconfiguration of the transfer function between particular solutions of FLPF and FHPF was proved to be applicable by the structure presented in this paper. Achieved results prove also possibility of electronic and mutually independent control of fractional-order and pole frequency by changing values of the parameters of the filter. Moreover, also electronic control of type of approximation was proven to be possible. Verification with the behavioral models is very useful because it helps to verify successfully the design correctness not only in PSpice simulations but also by measurements with real devices in laboratory experiments. The measured results in case of the electronic control of the order and also the pole frequency are in good agreement with theoretical expectations. Note that this paper is significantly extended version of paper published as Ref. 48.

\section{Acknowledgments}

Research described in this paper was financed by the National Sustainability Program under grant LO1401 and by the Czech Science Foundation under grant no. 16-06175S. For the research, infrastructure of the SIX Center was used.

\section{References}

1. M. Ortigueira, An Introduction to the fractional continuous-time linear systems: The 21st century systems, IEEE Circuits and Systems Magazine 8 (2008) 19-26.

2. A. S. Elwakil, Fractional-order circuits and systems: An emerging interdisciplinary research area, IEEE Circuits and Systems Magazine 10 (2010) 40-50.

3. T. Freeborn, A survey of fractional-order circuit models for biology and biomedicine, IEEE Journal on Emerging and Selected Topics in Circuits and Systems 3 (2013) 416-424.

4. A.S. Elwakil and B. Maundy, Extracting the Cole-Cole impedance model parameters without direct impedance measurement, Electron. Lett. 46 (2010) 1367-1368. 
5. T. J. Freeeborn, A. Elwakil and B. Maundy, Electrode location impact on Cole-impedance parameters using magnitude-only measurements, Proc. 59th IEEE Int. Midwest Symposium on Circuits and Systems (UAE, Abu Dhabi, 2016), pp. 21-24.

6. J. Valsa, P. Dvorak and M. Friedel, Network model of CPE, Radioengineering 20 (2011) 619626.

7. J. Valsa and J. Vlach, RC models of a constant phase element, International Journal of Circuit Theory and Applications 41(2013) 59-67.

8. B. M. Vinagre, I. Podlubny, A. Hernandez and V. Feliu, Some approximations of fractional order operators used in control theory and applications, Fractional Calculus \& Applied Analysis 3 (2000) 231-248.

9. J. Petrzela, T. Gotthans and Z. Hrubos, General review of the passive networks with fractionalorder dynamics, Proc. International Conference on Circuits, Systems, Control, Signals (2012), pp. 172-177.

10. J. Petrzela, Analog continuous-time filtering extended to fractional-order network elements, Proc. 36th Int. Conf. Telecommunications and Signal Processing TSP (2013), pp. 417-421.

11. J. Petrzela, Fundamental Analog Cells for Fractional-Order Two-Port Synthesis, Proc. 23rd Int. Conf. Radioelektronika (2013), pp. 182-187.

12. J. Petrzela, A note on fractional-order two-terminal devices in filtering applications, Proc. 24th Int. Conf. Radioelektronika (2014), pp. 1-4.

13. M. Tripathy, D. Mondal, K. Biswas and S. Sen, Experimental studies on realization of fractional inductors and fractional-order bandpass filters, International Journal of Circuit Theory and Applications 43 (2015) 1183-1196.

14. I. Dimeas, G. Tsirimokou, C. Psychalinos and A. Elwakil, Realization of Fractional-Order Capacitor and Inductor Emulators Using Current Feedback Operational Amplifiers, Proc. Int. Symposium on Nonlinear Theory and its Applications NOLTA (China, Hong Kong, 2015), pp. 237-240.

15. G. Tsirimokou, C. Psychalinos, A. S. Elwakil and K. N. Salama, Experimental verification of on-chip CMOS fractional-order capacitor emulators, Electronics Letters 52 (2016) 12981300 .

16. G. Tsirimokou, C. Psychalinos and A. S. Elwakil, Emulation of a constant phase element using operational transconductance amplifiers, Analog Integrated Circuits and Signal Processing 85 (2015) 413-423.

17. G. Tsirimokou, C. Laoudias and C. Psychalinos, 0.5-V fractional-order companding filters, International Journal of Circuit Theory and Applications 43 (2015) 1105-1126.

18. G. Tsirimokou and C. Psychalinos, Ultra-low voltage fractional-order circuits using current mirrors, International Journal of Circuit Theory and Applications 44 (2016) 109-126.

19. T. Freeborn, B. Maundy and A. Elwakil, Field programmable analogue array implementation of fractional step filters, IET Circuits, Devices and Systems 4 (2010) 514-524.

20. B. Maundy, A. Elwakil and T. Freeborn, On the practical realization of higher-order filters with fractional stepping, Signal Processing 91(2011) 484-491.

21. R. Sotner, J. Jerabek, J. Petrzela and T. Dostal, Simple Approach for Synthesis of FractionalOrder Grounded Immittances Based on OTAs, Proc. Int. Conf. Telecommunications and Signal Processing TSP (2016), pp. 563-568.

22. R. Sotner, J. Jerabek, N. Herencsar, J. Petrzela, T. Dostal and K. Vrba, First-order adjustable transfer sections for synthesis suitable for special purposes in constant phase block approximation, International Journal of Electronics and Communications 69 (2015) 13341345.

23. M. Krishna, S. Das, K. Biswas and B. Goswami, Fabrication of a fractional order capacitor with desired specifications: a study on process identification and characterization, IEEE Trans. Electron Devices 58 (2011) 4067-4073. 
24. A. M. Elshurafa, M. N. Almadhoun, K. N. Salama and H. N. Alshareef, Microscale electrostatic fractional capacitors using reduced graphene oxide percolated polymer composites, Applied Physics Letters 102 (2013) 232901-4.

25. A. Adhikary, M. Khanra, S. Sen and K. Biswas, Realization of carbon nanotube based electrochemical fractor, Proc. IEEE Int. symposium on Circuits and Systems ISCAS (Portugal, Lisbon, 2015), pp. 2329-2332.

26. P. Ushakov, A. Shadrin, D. Kubanek and J. Koton, Passive Fractional-Order Components Based On Resistive- Capacitive Circuits With Distributed Parameters, Proc. 39th Int. Conf. Telecommunications and Signal Processing TSP (2016), pp. 638-642.

27. P. Ahmadi, B. Maundy, A. Elwakil and L. Belostotski, High-quality factor asymmetric-slope band-pass filters: a fractional-order capacitor approach, IET Circuits, Devices and Systems 6 (2012) 187-197.

28. M. Tripathy, K. Biswas and S. Sen, A design example of a fractional-order KerwinHuelsman-Newcomb biquad filter with two fractional capacitors of different order, Circuits Systems and Signal Processing 32 (2013) 1523-1536.

29. A. Ali, A. Radwan and A. Soliman, Fractional order Butterworth filter: active and passive realizations, IEEE Journal on Emerging and Selected Topics in Circuits and Systems 3 (2013) 346-354.

30. A. Soltan, A. G. Radwan and A. M. Soliman, Fractional Order Sallen-Key and KHN filters: Stability and Poles Allocation, Circuits Systems and Signal Processing 34 (2015) 1461-1480.

31. T. Freeborn, B. Maundy and A. Elwakil, Toward the realization of fractional step filters, Proc. IEEE International Symposium on Circuits and Systems ISCAS (France, Paris, 2010), pp. $1037-1040$.

32. B. Maundy, A. Elwakil and T. Freeborn, On the practical realization of higher-order filters with fractional stepping, Signal Processing 91 (2011) 484-491.

33. F. Khateb, D. Kubanek, G. Tsirimokou and C. Psychalinos, Fractional-order filters based on low-voltage DDCCs, Microelectronics Journal 50 (2016) 50-59.

34. G. Tsirimokou, C. Psychalinos and A. S. Elwakil, Fractional-order electronically controlled generalized filters, Int. Journal of Circuit Theory and Applications (2016). Online first, doi: 10.1002/cta.2250.

35. J. Dvorak, L. Langhammer, J. Jerabek, J. Koton, R. Sotner and J. Polak, Electronically Tunable Fractional-Order Low- Pass Filter with Current Followers, Proc. 39th International Conference on Telecommunications and Signal Processing TSP (2016), pp. 587-592.

36. D. Biolek, R. Senani, V. Biolkova and Z. Kolka, Active elements for analog signal processing: Classification, Review and New Proposals, Radioengineering 17 (2008) 15-32.

37. J. Jerabek, J. Koton, R. Sotner and K. Vrba, Adjustable band-pass filter with current active elements: two fully-differential and single-ended solutions, Analog integrated circuits and signal processing 74 (2013) 129-139.

38. G. E. Carlson and C. A. Halijak, Approximation of fractional capacitors $(1 / \mathrm{s})^{\wedge}(1 / \mathrm{n})$ by a regular Newton process, IEEE Transactions on Circuit Theory 11 (1964) 210-213.

39. K. Matsuda and H. Fujii, $\mathrm{H}_{\infty}-$ optimized wave-absorbing control: analytical and experimental results, Journal of Guidance, Control, and Dynamics 16 (1993) 1146-1153.

40. A. Oustaloup, Systèmes Asservis Linéaires d'Ordre Fractionnaire: Théorie et Pratique (Masson: Paris, 1983).

41. A. Oustalou, La Dérivation Non Entière, Théorie, Synthèse et Applications (Hermes Science Publications, Paris, 1995).

42. A. Oustaloup, F. Levron, B. Mathieu and F. Nanot, Frequency-band complex non integer differentiator: characterization and synthesis, IEEE Transactions on Circuits and Systems - I: Fundamental Theory and Applications 47 (2000) 25-39. 
43. A. Djouambi, A. Charef and A. Besançon, Optimal approximation, simulation and analog realization of the fundamental fractional order transfer function, International Journal of Applied Mathematics and Computer Science 17 (2007) 455-462.

44. C. Gruau, D. Picart, R. Belmas, E. Bouton, F. Delmaire-Sizes, J. Sabatier and H. Trumel, Ignition of a confined high explosive under low velocity impact. International Journal of Impact Engineering 36 (2009) 537-550.

45. B. Krishna and K. Reddy, Active and passive realization of fractance device of order $1 / 2$, Active and Passive Electronic Components Hindawi Publishing Corporation 2008 (2008) 1-5.

46. L. Kadlcik and P. Horsky, A Low-Dropout Voltage Regulator with a Fractional-Order Control, Radioengineering 25 (2016) 312-320.

47. J. Jerabek and K. VRBA, SIMO type low-input and high-output impedance current- mode universal filter employing three universal current conveyors, $A E U$ - International Journal of Electronics and Communications, 64 (2010) 588-593.

48. J. Jerabek, R. Sotner, D. Kubanek, J. Dvorak, L. Langhammer, N. Herencsar and K. Vrba, Fractional-Order Low-Pass Filter with Electronically Adjustable Parameters, Proc. Int. Conference on Telecommunications and Signal Processing (Vienna, Austria, 2016), pp. 569574.

49. J. Jerabek, R. Sotner, J. Dvorak, L. Langhammer, and J. Koton, Fractional-order high-pass Filter with electronically adjustable parameters, Proc. 2016 International Conference on Applied Electronics (AE) (Pilsen, Czech Republic, 2016), pp. 111-116.

50. Datasheet EL2082 (Elantec), Current-mode multiplier (intersil, rev. D, 1996). Available online at <http://www.intersil.com/content/dam/Intersil/documents/el20/el2082.pdf>. 